\title{
Determination of Correlation Coefficients for RazakSAT Received Signals
}

\author{
A. B. Basri ${ }^{1}$, K. Badron ${ }^{1}$, A. F. Ismail ${ }^{1}$, A. Chanik ${ }^{2}$, S. F. Jamil ${ }^{2}$ and H. Salim ${ }^{2}$ \\ ${ }^{1}$ Department of Electrical and Computer Engineering, Kulliyyah of Engineering, \\ International Islamic University Malaysia (IIUM), \\ Jin. Gombak, Selangor, Malaysia \\ ${ }^{2}$ National Space Agency (ANGKASA), Malaysia Space Centre \\ 42700 Banting, Selangor \\ atikahbalqis32@gmail.com, khairayu@iium.edu.my,af_ismail@iium.edu.my, \\ abadi@angkasa.gov.my,fara@angkasa.gov.my,hamid@angkasa.gov.my
}

\begin{abstract}
RazakSAT is the second Malaysian Earth observation satellite operating with downlink frequency of $2.232 \mathrm{GHz}$ (S-band). RazakSAT's received signals had been recorded in percentage unit and the values are required be quantified in the common signal strength unit, dBm. This paper details how such has been achieved. Measurements were carried out in order to establish the correlation between the percentage values and dBm values. The campaign involved the setting-up of a terrestrial microwave link transmission comprised of a transmitter, a receiver, and relevant antennas at about $500 \mathrm{~m}$ displacement. The transmitted power was controlled with the use of a signal generator and the received power level was measured using a spectrum analyzer. Appropriate coefficients for the correlation had been determined. The slope coefficient, $m$ has been derived to have the value of 0.7765 and its slope intercept coefficient, $c$ has the value of 85.301. Using these coefficients, the received satellite signals can then be converted into $\mathrm{dBm}$.
\end{abstract}

Keywords: Transmitter, Receiver, S-band, Terrestrial microwave link

\section{Introduction}

The RazakSAT satellite mission was a self-funded initiative by Malaysian Government. RazakSAT is a high-resolution remote sensing satellite positioned at the Near Equatorial Orbit (NEqO). Malaysia can have huge benefits of a NEqO satellite where due to such geographical position, it allows the satellite to revisit any desired coverage area up to 14 times per day [1]. From the baseline circular orbit of $685 \mathrm{~km}$ altitude with up to 9 degrees inclination, regions in Malaysia can be regularly monitored [2]. The satellite communication system is divided into two major segments namely the space segment and Earth segment as shown in Figure 1 below. The space segment consists of an on-board Sband transceiver, an X-band image transmitter unit, and related modulators as well as demodulators. The Earth segment is a combination of the Mission Control Centre and Image Receiving Centre [3]. The received signal strength during RazakSAT operation was recorded in percentage instead of the typical $\mathrm{dBm}$ unit. This caused serious complication during the analysis of link budget calculation or link performance evaluation. The percentage has to be accurately converted into unit of $\mathrm{dBm}$ in order to enable any mathematical computation. The paper is organized in the following manners where its first section covers the introduction and some brief relevant background summaries. It then continues with Section 2 that outlines the measurement setup. The measurement results and

Received (August 24, 2017), Review Result (November 15, 2017), Accepted (November 26, 2017) 
analyses are elaborated in Section 3. The conclusion and research way forward are pointed out in Section 4.

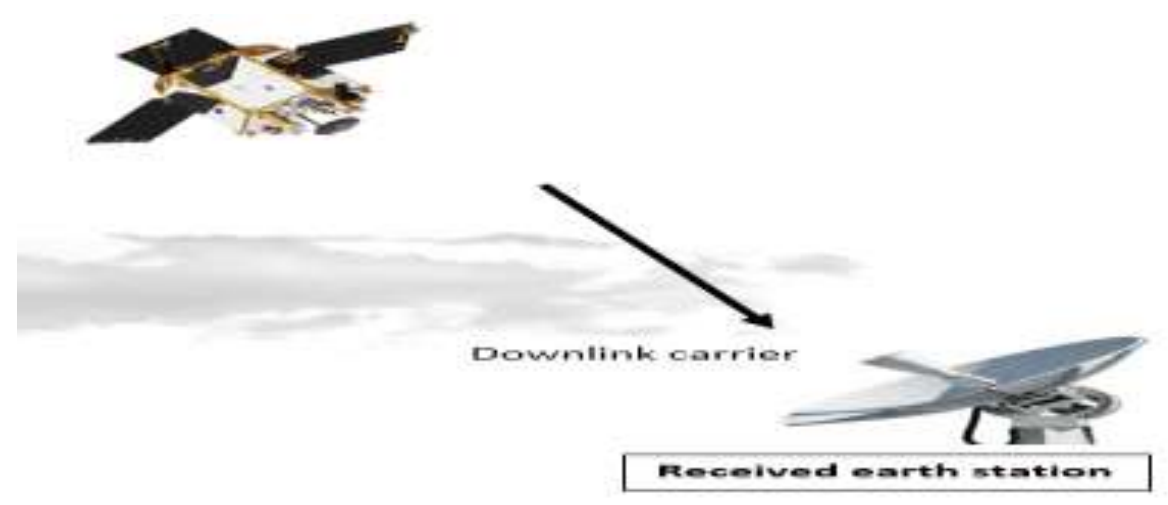

Figure 1. RazakSAT Operational Segment

The site measurement was carried out with specific prior objectives. The main ideas focused around the discussions and the analyses requirement involving:

- How to design a terrestrial microwave link system operating with S-band frequency.

- How to determine the correlation coefficients to convert the RazakSAT track receiver measurements. The recorded value denotes the received signal value from the satellite receiver. The correct unit has to be determined because it is critical when performing any analysis that involves the received signal value.

Several considerations had taken place specifically familiarization of what S-band is all about. The S-band is one of the microwave bands within the electromagnetic spectrum. According to IEEE standards, S-band is referred as frequency between 2 to 4 gigahertz $(\mathrm{GHz})$. This means it crosses the convectional boundary between the UHF and SHF bands at $3 \mathrm{GHz}$ [4]. The fundamental understanding is a requirement in the setting-up of any transmit and receive configuration. In all cases, the appropriate antenna with adequate performance capability must be identified. The significant properties of every antenna are the radiation pattern and the antenna gain, which refers to the magnitude of the signals for both transmitter and receiver. The radiation pattern is the dependence of strength of the radio wave that radiated at the different directions. The radiation pattern leads to the power radiated by the antenna and can be focused in a particular direction where produce of directivity is typically expressed in terms of power gain [4].

\subsection{Microwave Line of Sight System}

The microwave frequencies range between $300 \mathrm{MHz}$ to $30 \mathrm{GHz}$. They encompasses wavelength of $1 \mathrm{~m}$ down to $1 \mathrm{~cm}$. These frequencies have been widely exploited for terrestrial and even for satellite communication systems [5]. To ensure that both transmitter and receiver are able to communicate between both systems without being blocked by the curvature of the Earth, line of sight requirement which depends on the height placement of the antennas needs to be determined. A schematic diagram for transmitter and the receiver in the measurement exercise is as shown in Figure 2 below. For the point-to-point radio link transmission setup, the antennas had to be positioned above any tower or other tall structures at sufficient height, capable to provide the direct and unblock radio horizon between transmitter and receiver system. 


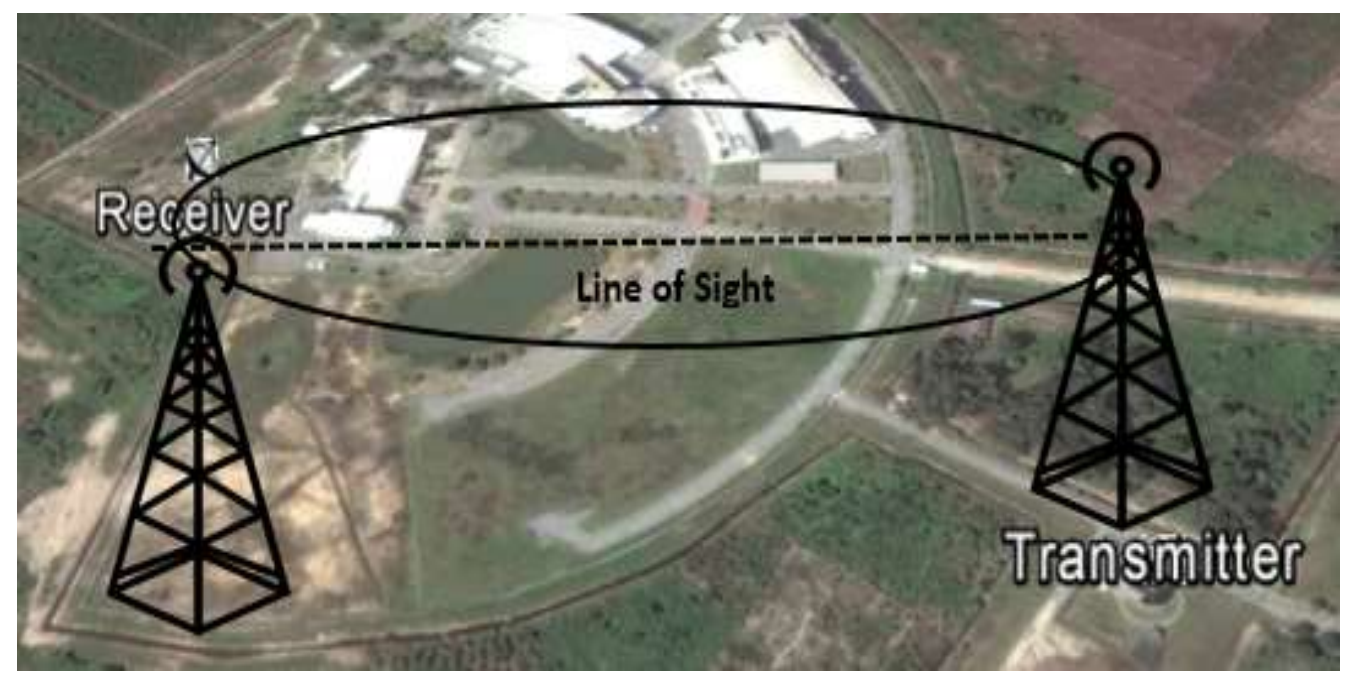

Figure 1. Line of Sight from Transmitter to Receiver

\subsection{Standards}

In the United States, radio channel allocation is controlled by the Federal Communication Commission (FCC) while in Malaysia the authorized entity is the Malaysian Communication and Multimedia Commission (MCMC). Every country has different regulation for the licensing of microwave radio links, however they are all for the same purpose which is to provide regulatory protection to any interference that affected the receiver system [6]. The regulations include the transmitter power limits, frequency allocation, emission limit and antenna directivity. In the experimental campaign, all allowable performance parameters of terrestrial fixed services digital radio communication equipment's operating at $2.232 \mathrm{GHz}$ frequency band were observed. The measurement setup adhered to all national and international performance regulations. Apart from the conventional regulations, the experiment also observed Automatic Transmit Power Control (ATPC) condition. ATPC is known as the power interval from the maximum output power level where including the tolerances to the lowest transmitter output power level. At all times, ATPC value range is supposed to be not less than $10 \mathrm{~dB}$ [7].

As the distance between the transmitter and receiver increases, the signal power decreases, all else being equal. At some point the received signal power will be less than the noise that is received or generated by the receiver and reliable communications will not be possible. The greatest contribution to the decrease of received signal power is the loss due to the propagation distance known as the path loss or free space loss. The Equation 1 below is known as the link equation and it is essential in the calculation of power received in any radio link [8].

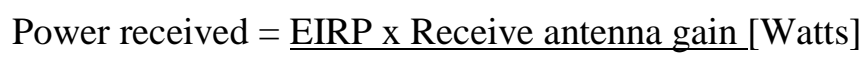

Path Loss

\section{Experimental Setup}

An Agilent signal generator model number N9310A was used to generate the S-band signal with center frequency of $2.232 \mathrm{GHz}$. This signal generator is able to generate waveform between $9 \mathrm{kHz}$ to $3.0 \mathrm{GHz}$ with resolution of $0.1 \mathrm{~Hz}$. The signal generator was positioned in the transmit antenna tower located $450.30 \mathrm{~m}$ away from the receive antenna. The minimum and maximum transmit power was $-10 \mathrm{dBm}$ and $10 \mathrm{dBm}$ respectively. $5 \mathrm{dBm}$ increase was applied for every subsequent transmissions until the maximum level. For every transmission, received signal level was recorded automatically by the track receiver 
in percentage unit. A Keysight handheld spectrum analyzer model number N9340B was used to measure the corresponding received signal in $\mathrm{dBm}$ unit. This handheld spectrum analyzer is capable to detect frequency for ranges from $100 \mathrm{kHz}$ up to $3 \mathrm{GHz}$. The outline for the measurement setup is as shown in Figure 3 below. Both transmit and receive antennas are located within the compound of National Space Agency (ANGKASA), Sungai Lang, Banting. The location setup for the site measurement is as portrayed in Figure 4. Snapshots of the technical crew while carrying out the measurement are shown in Figure 5 below.

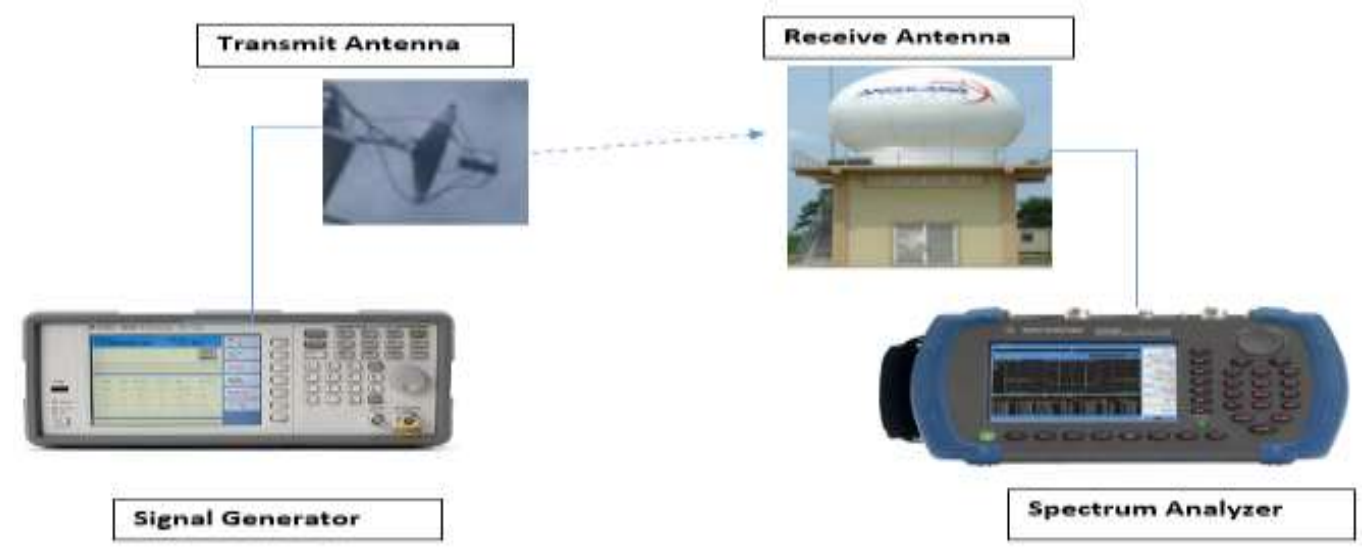

Figure 3. Setup for Power Received Measurement

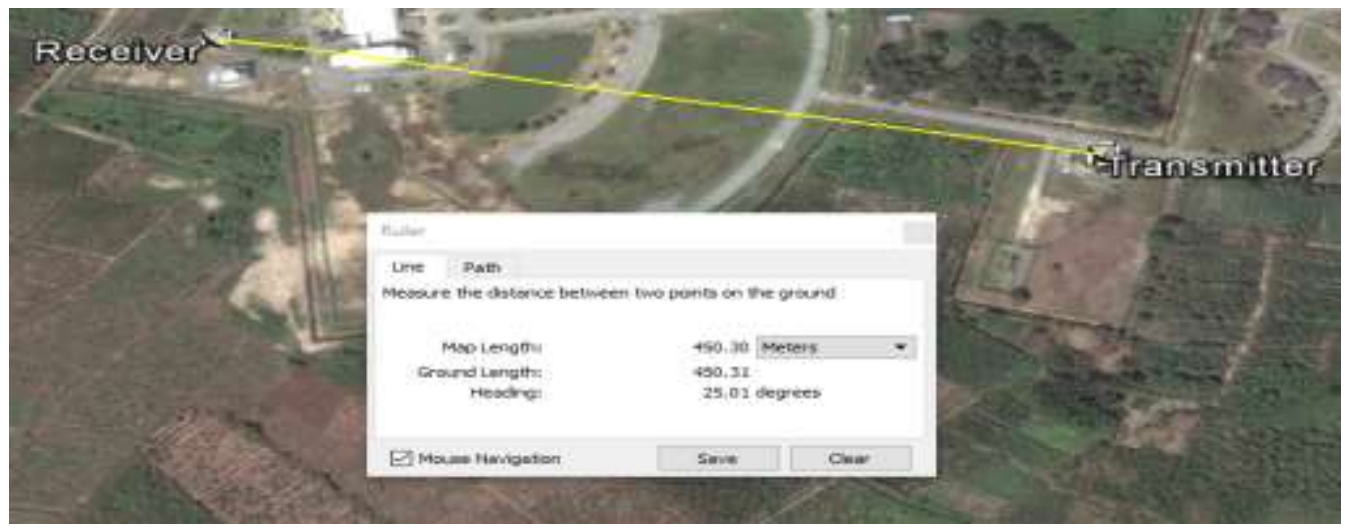

Figure 4. Location of Receiver and Transmitter

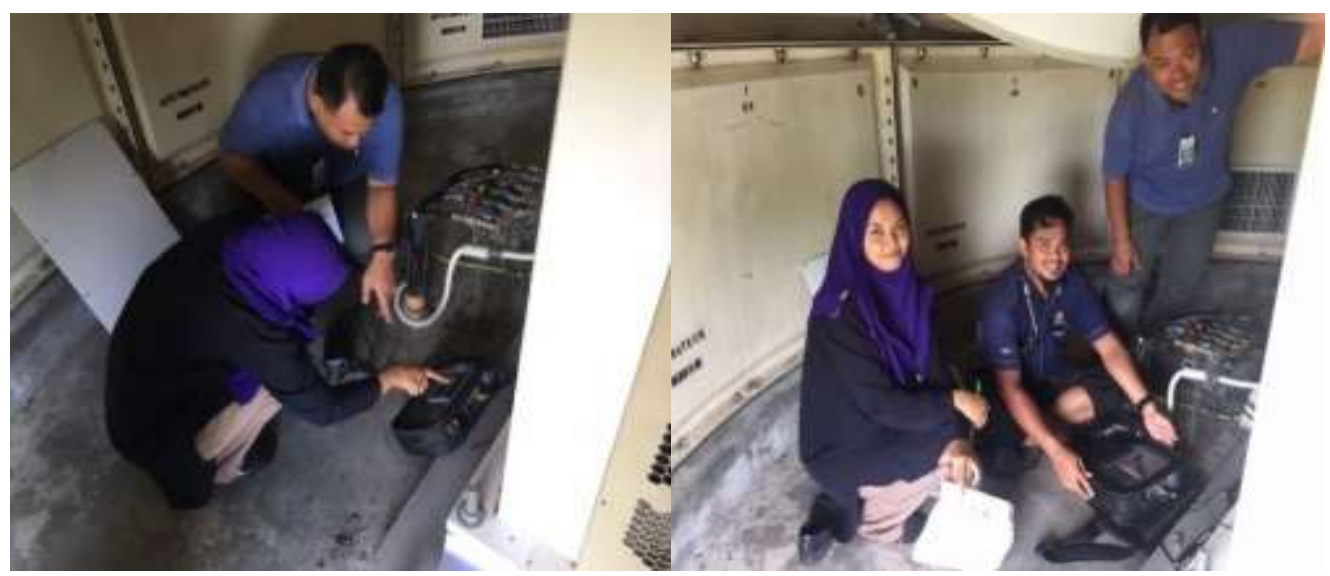

Figure 5. Technical Crew for Measurement Setup 


\section{Result and Analysis}

\subsection{Free Space Path Loss Calculation}

Free space path loss measures the power loss in free space where no interferences or obstacle exist [9]. FSPL is highly dependent namely on two parameters; frequency and distance of the radio wave transmission as listed in equation 2 below [10].

$$
\begin{aligned}
& \text { Where FSPL }(\mathrm{dB})=20 \log _{10}(\mathrm{~d})+20 \log _{10}(\mathrm{f})+\mathrm{K} \\
& \text { Where } \mathrm{d}=\text { distance }(\mathrm{km}) \\
& \mathrm{f}=\text { frequency }(\mathrm{GHz}) \\
& \mathrm{K}=\text { Constant depend on units use in distance and frequency }
\end{aligned}
$$

FSL for distance of $450.30 \mathrm{~m}$ and frequency of $2.232 \mathrm{GHz}$ would have resulted:

$$
\begin{aligned}
& 20 \log _{10}(0.45030)+20 \log _{10}(2.232)+92.45 \\
& =92.49396 \mathrm{~dB}
\end{aligned}
$$

$\mathrm{R}_{\mathrm{X}}$ Power $(\mathrm{dBm})=\mathrm{T}_{\mathrm{X}}$ Power $(\mathrm{dBm})+\mathrm{T}_{\mathrm{X}}$ antenna gain $(\mathrm{dBi})+\mathrm{R}_{\mathrm{X}}$ antenna gain $(\mathrm{dBi})-$

$T_{x}$ Cable losses $(d B)-R_{X}$ cable Losses $(d B)-$ FSPL $(d B)$

Equation 3 expressed above is essential in the determination of power received of any radio link. The received power value at the track receiver should be in $\mathrm{dBm}$ unit and therefore, all percentage values of RazakSAT received signal have to be converted accordingly. It is crucial to know the correlation and all applicable coefficient values in the process of converting percentages into $\mathrm{dBm}$. During the measurement process; the track receiver power received value in the unit of percentage was recorded together with the reading of the spectrum analyzer in $\mathrm{dBm}$. Figure 6 below shows an example of print screen for a received signal level in $\mathrm{dBm}$. A $5 \mathrm{dBm}$ signal was transmitted using Left Hand Circular Polarization (LHCP). The spectrum analyzer detected the received signal at value of -34.77 $\mathrm{dBm}$. The track receiver in this case indicated the value of 67.02 percent

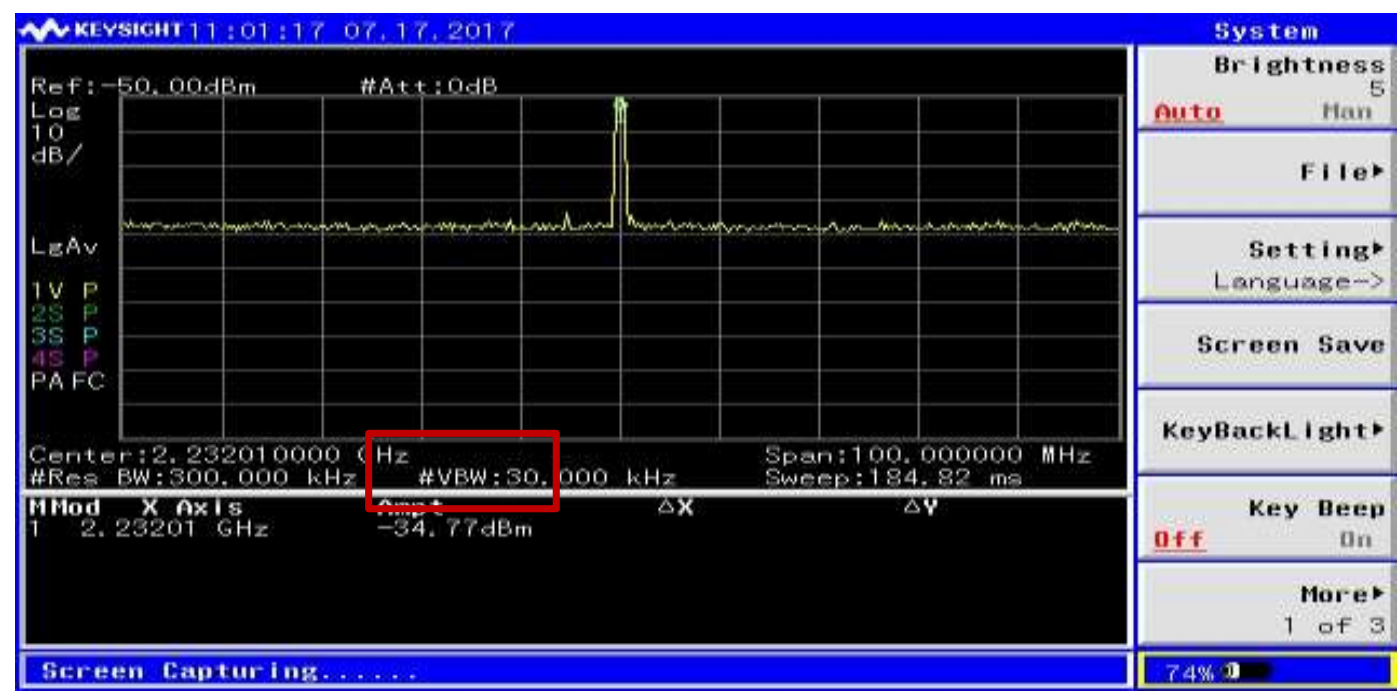

Figure 6. Received Signal Level when 5 dBm Transmit Power in LHCP

Table 2 below displays the recorded measurements for both LHCP and Right Hand Circular Polarization (RHCP) detected by the RazakSAT S-band track receiver. From the collected results, a graph was plotted in order to determine the best-fit correlation. From the correlation, appropriate coefficients were determined for converting the RazakSAT track receiver values in percentage into $\mathrm{dBm}$. 


\section{Table 2. Measurement of Power Received at Track Receiver for RazakSAT} 2.232 GHz Downlink Frequency

\begin{tabular}{|c|c|c|}
\hline \multicolumn{3}{|l|}{ RHCP - 229} \\
\hline $\begin{array}{l}\text { Signal transmitted } \\
(\mathrm{dBm})\end{array}$ & $\begin{array}{l}\text { Received at track receiver }(\%) \\
-14 \text { th July }\end{array}$ & $\begin{array}{l}\text { Power received at track } \\
\text { spectrum analyser }(\mathrm{dBm})\end{array}$ \\
\hline-10.0 & 50.13 & -45.59 \\
\hline-5.0 & 55.13 & -40.61 \\
\hline 0.0 & 59.98 & -35.61 \\
\hline 5.0 & 67.64 & -30.39 \\
\hline 10.0 & 75.15 & -27.94 \\
\hline \multicolumn{3}{|l|}{ LHCP - 201} \\
\hline $\begin{array}{l}\text { Signal transmitted } \\
(\mathrm{dBm})\end{array}$ & $\begin{array}{l}\text { Received at track receiver }(\%) \\
-14 \text { th July }\end{array}$ & $\begin{array}{l}\text { Power received at spectrum } \\
\text { analyser }(\mathrm{dBm})\end{array}$ \\
\hline-10.0 & 49.97 & -49.47 \\
\hline-5.0 & 53.72 & -44.35 \\
\hline 0.0 & 60.29 & -39.55 \\
\hline 5.0 & 67.02 & -34.77 \\
\hline 10.0 & 71.53 & -30.61 \\
\hline
\end{tabular}

The measured results above are tabulated on a graph and the best curve-fit line plot was produced. By using the plot, a correlation was identified and the coefficient values were determined. The process of determining the correlation is shown in the Figure 7 below. The coefficients and their values are listed in Table 3. By using the values, the $\mathrm{dBm}$ values for the received signal levels logged by the RazakSAT track receiver can be determined. An example where received signal in percentage was converted into $\mathrm{dBm}$ for $15^{\text {th }} \mathrm{July} 2009$ is presented in Figure 8 below.

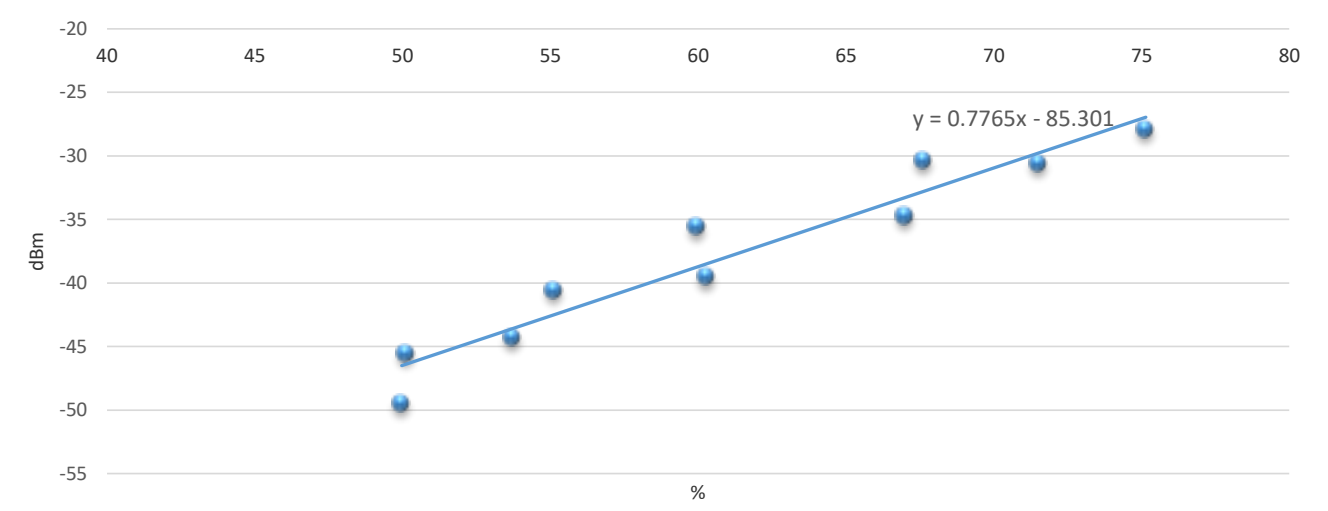

Figure 7. Correlation Coefficient for RazakSAT S-band Received Signal Value

Table 3. Coefficients

\begin{tabular}{|c|c|c|}
\hline Coefficients & Symbols & Values \\
\hline Slope coefficient & $\mathrm{M}$ & 0.7765 \\
\hline Slope intercept coefficient & $\mathrm{C}$ & 85.301 \\
\hline
\end{tabular}



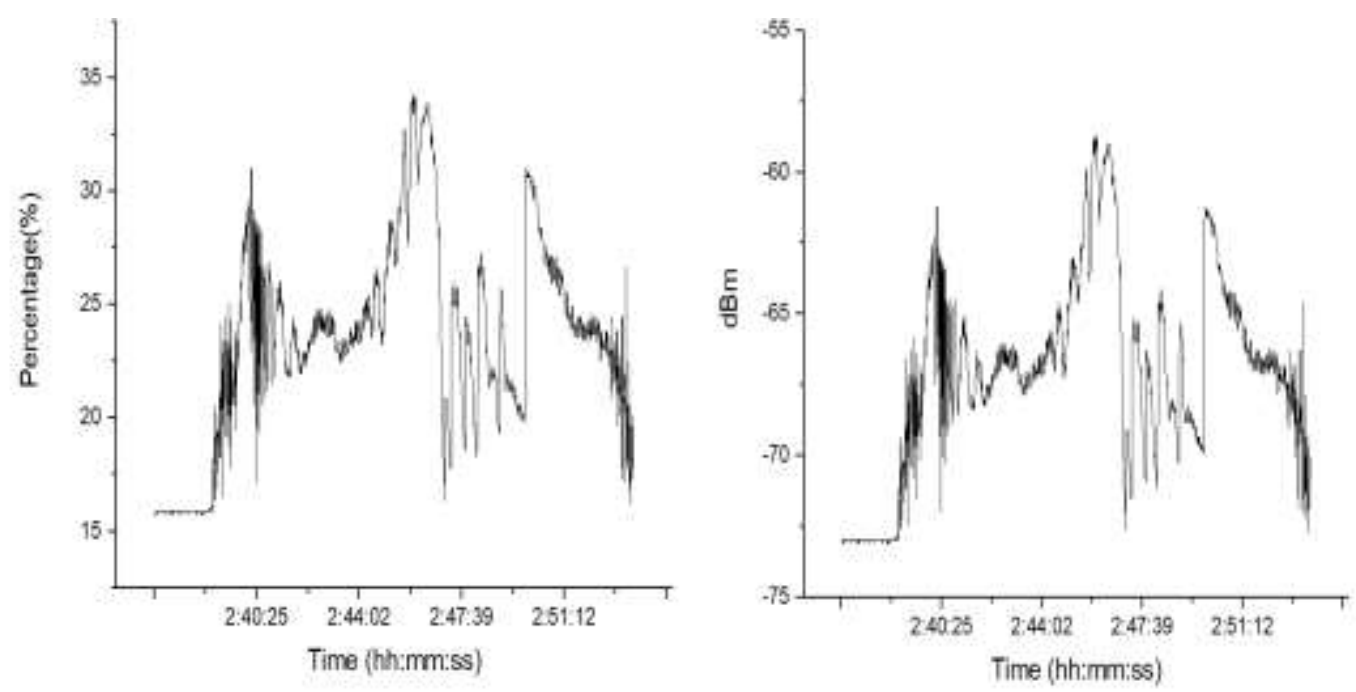

Figure 8. Conversion for RazakSAT S-band Received Signal Value $(15 / 7 / 2009)$

\section{Conclusion}

From the measurement campaign, required values of RazakSAT's received signal levels in $\mathrm{dBm}$ unit had been established. This was achieved by conducting concurrent measurements using the track receiver and a spectrum analyzer. Conversion from percentage into $\mathrm{dBm}$ was attained by mapping the percentage value using a derived correlation and its associated coefficients. The finding of this research i.e., received signal levels in $\mathrm{dBm}$ are indeed extremely useful in the microwave propagation studies. Assessments can now be made concerning the effect of hydrometeors on any S-band space to Earth communication link as well as applicable mitigation technique in combating the rain fade. Subsequently the findings can also offer insight for development of a revised free space path loss formulation for satellites operating in tropical countries.

\section{Acknowledgments}

All the authors would like to acknowledge the Research Management Centre of the International Islamic University Malaysia (IIUM) and Malaysian Ministry of Education (MOHE) for the financial assistance and support throughout the research. Our special recognitions to ANGKASA expertise in return for their ongoing support. The reported research outcome is part of the deliverables for the research funded under IIUM's Research University Initiatives. This research is being sponsored under the Fundamental Research Grant Scheme (FRGS) Research Project by Malaysian Ministry of Education in generation of new theories, concepts and ideas.

\section{References}

[1] A. A. Abiodun, "Future trends in the global space arena: Challenges and opportunities for Africa", African Skies, vol. 12, no. 12, (2008).

[2] H. J. Chun, B. J. Kim, H. S. Chang, E. E. Kim, W. K. Park, S. D. Park and A. Ashard, "RazakSAT-A High Performance Satellite Waiting for Its Mission in Space", (2006).

[3] N. S. Wai, A. A. Tan, J. W. S. Mee, M. Ismail and M. D. Subari, "Preflight radiometric calibration of RazakSAT TM", In Recent Advances in Space Technologies, 2009. RAST'09. 4th International Conference on IEEE, (2009) June, pp. 277-282.

[4] D. Misra, "Radio-frequency and microwave communication circuits: analysis and design", John Wiley \& Sons, (2004).

[5] K.-L. Du and M. NS Swamy, "Wireless communication systems: from RF subsystems to 4G enabling technologies", Cambridge University Press, (2010). 
[6] D. J. Withers, "Radio spectrum management: management of the spectrum and regulation of radio services", IET, vol. 45, (1999).

[7] G. Venkateswarlu, "Studies on Maximum Power Point Tracking Techniques for PV cells using evolutionary Algorithms", (2014).

[8] C. Phillips, D. Sicker and D. Grunwald, "A survey of wireless path loss prediction and coverage mapping methods", IEEE Communications Surveys \& Tutorials, vol. 15, no. 1, (2013), pp. 255-270.

[9] Y. Zakaria, L. Ivanek and I. Glesk, "Propagation measurements and estimation of channel propagation models in urban environment”, KSII Transactions on Internet and Information Systems, vol. 11, no. 5, (2017), pp. 2453-2467.

[10] Y. Salem and L. Ivanek, "Propagation modelling of path loss models for wireless communication in urban and rural environments at 1800 GSM frequency band", Advances in Electrical and Electronic Engineering, vol. 14, no. 2, (2016), pp. 139.

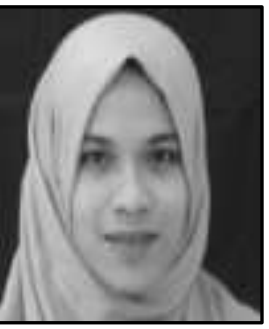

Authors

A. B. Basri, graduated in 2014 B. Eng and 2017 MSc in Communication from the International Islamic University Malaysia (IIUM). She is currently a research officer whilst pursuing her Ph.D studies at the Electrical and Computer Engineering Department, IIUM. Her research interests are in radar radiometry and wireless communication.

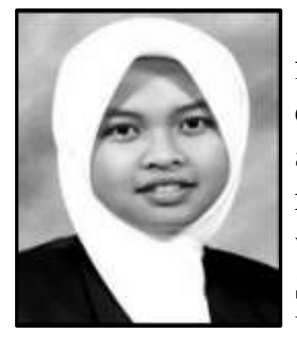

K. Badron, obtained her BEng (2006), Msc (2011) and Ph.D (2016) from International Islamic University Malaysia (IIUM). She is currently one of the faculty members of Faculty of Engineering, IIUM and recently commenced her research areas in Radar and Radiometry research, quantifying propagation effects on microwave and millimetre wave links. Khairayu is a member of IEEE, IEM, BEM and MTSFB. She has published and co-authored more than 15 papers in International Journals as well as Conferences on subjects relating to rain attenuation in the tropical regions.

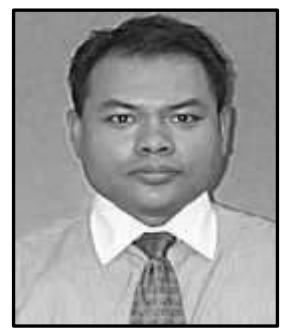

A.F. Ismail, currently a lecturer at Department of Electrical and Computer Engineering, Faculty of Engineering, International Islamic University Malaysia (IIUM). He completed his bachelor degree studies in Electrical Engineering at Gannon University, Pennsylvania, USA with Cum Laude Latin honors. He holds MSc and $\mathrm{PhD}$ from University of Essex, UK and University of Bath, UK, respectively. His research interests include development of active and passive target tracking algorithms, radio frequency and wireless systems and microwave and milimetrewave technology. He is registered with Board of Engineering Malaysia as a Professional Engineer and also a senior member of IEEE.

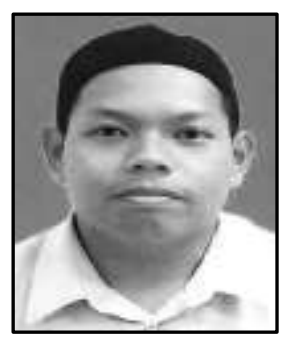

Abadi Chanik gained the B.E. degree in electronic engineering from the Universiti Malaysia Sarawak, Malaysia, in 2005. He is currently awaiting the approval for his $\mathrm{PhD}$ from the University of Surrey in the field of spacecraft control. He is a member of the Board of Engineers (BEM) Malaysia and since 2006, he is a Research Officer with the Malaysia Space Agency (ANGKASA). His work includes the operation of the Malaysian and other satellites from neighboring country specifically in the ground segments. 


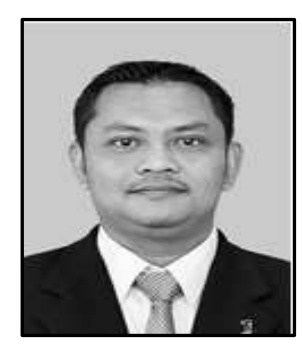

Hamid Salim, currently a research officer at Agensi Angkasa Negara (ANGKASA), Ministry of Science, Technology and Innovation (MOSTI). He completed his Bachelor Degree studies in Kolej Universiti Teknologi Tun Hussein Onn (KUiTTHO). He holds MSc from Universiti Teknologi MARA (UiTM) majoring in Telecommunication and Information Engineering. He involve in the $R \& D$ activity in space development for the low cost mission including RazakSAT.

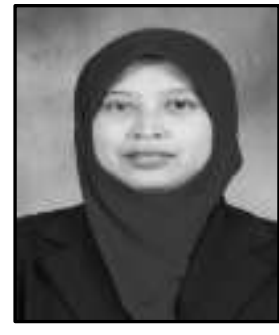

S. Farasahida Jamil, obtained her diploma in electronic (computer) engineering from the Ungku Omar Polytechnic Perak, Malaysia, in 2004. She is currently a research officer assistant at the Malaysia National Space Agency (ANGKASA). Her work includes the operation of the Malaysian and other satellites from neighboring country specifically in the ground segments. Her research interest is in the development of a satellite ground facility and its communication links. 
International Journal of Future Generation Communication and Networking Vol. 11, No. 2 (2018) 